\title{
Erratum to: Nocebo Effects and Mild Traumatic Brain Injury: Legal Implications
}

\author{
Rodney D. Vanderploeg • Heather G. Belanger • \\ Paul M. Kaufmann
}

Published online: 24 October 2014

(C) Springer Science+Business Media New York 2014

Erratum to: Psychol. Inj. and Law (2014) 7(3):245-254

DOI 10.1007/s12207-014-9201-3

The original version of this article unfortunately contained a mistake. The below Acknowledgment was missing.

The research reported here was supported in part by the Department of Veterans Affairs, Veterans Health Administration, and the Defense and Veterans Brain Injury Center. Further support was provided by the James A. Haley Veterans' Hospital. The views expressed herein are those of the authors and do not necessarily reflect the views or the official policy of the Department of Veterans Affairs or U.S. Government.

The online version of the original article can be found at $\mathrm{http}$ ://dx.doi.org/ 10.1007/s12207-014-9201-3.

R. D. Vanderploeg $(\bowtie) \cdot$ H. G. Belanger

MHBS/Psychology (116B), James A. Haley Veterans' Hospital,

13000 Bruce B. Downs Blvd., Tampa, FL 33612, USA

e-mail: Rodney.Vanderploeg@va.gov

R. D. Vanderploeg $\cdot$ H. G. Belanger

Department of Psychology, University of South Florida, Tampa, FL,

USA

R. D. Vanderploeg $\cdot$ H. G. Belanger

Departments of Psychiatry and Behavioral Neurosciences,

University of South Florida, Tampa, FL, USA

R. D. Vanderploeg $\cdot$ H. G. Belanger

Defense and Veterans Brain Injury Center, Tampa, FL, USA

P. M. Kaufmann

University of Arizona, Tucson, AZ, USA 